\title{
Rediscovery of Laura's glassfrog Nymphargus laurae (Anura: Centrolenidae) with new data on its morphology, colouration, phylogenetic position and conservation in Ecuador
}

\author{
María José Sánchez-Carvajal ${ }^{1,2}$, Grace Carolina Reyes-Ortega ${ }^{1,2}$, Diego Francisco Cisneros-Heredia ${ }^{3,4}$, H. Mauricio \\ Ortega-Andrade ${ }^{\text {Corresp. 1,2,4 }}$ \\ 1 \\ ${ }^{1}$ Ingeniería en Ecosistemas, Facultad de Ciencias de la Vida, Universidad Regional Amazónica Ikiam, Tena, Napo, Ecuador \\ 2 Grupo de Investigación en Biogeografía y Ecología Espacial, Universidad Regional Amazónica Ikiam, Tena, Napo, Ecuador \\ ${ }^{3}$ Colegio de Ciencias Biológicas y Ambientales, Instituto de Biodiversidad Tropical iBIOTROP, Museo de Zoología, Laboratorio de Zoología Terrestre, \\ Universidad San Francisco de Quito, Quito, Pichincha, Ecuador \\ 4 División de Herpetología, Instituto Nacional de Biodiversidad, Quito, Pichincha, Ecuador \\ Corresponding Author: H. Mauricio Ortega-Andrade \\ Email address: mauricio.ortega@ikiam.edu.ec
}

We report the rediscovery of Laura's Glassfrog, Nymphargus laurae Cisneros-Heredia and McDiarmid, 2007, based on two specimens collected at the Colonso-Chalupas Biological Reserve, province of Napo, Ecuador. The species was described and known from a single male specimen collected in 1955 at Loreto, north-eastern Andean foothills of Ecuador. Limited information was available about the colouration, systematics, ecology, and biogeography of $N$. laurae. We provide new data on the external morphology, colouration, distribution and comment on its conservation status and extinction risk. We discuss the phylogenetic relationships of $N$. laurae, which forms a clade together with $N$. siren and $N$. humboldti. The importance of research in unexplored areas must be a national priority to document the biodiversity associated, especially in protected areas. 


\section{Rediscovery of Laura's Glassfrog Nymphargus laurae (Anura:}

2 Centrolenidae) with new data on its morphology, colouration, phylogenetic position and conservation in Ecuador

María José Sánchez-Carvajal ${ }^{1,2}$, Grace C. Reyes-Ortega ${ }^{1,2}$, Diego F. Cisneros-Herediaa ${ }^{3,4}, \mathrm{H}$. Mauricio Ortega-Andrade $2,4, *$

${ }^{1}$ Ingeniería en Ecosistemas, Facultad de Ciencias de la Vida, Universidad Regional Amazónica Ikiam, km 7 road to Muyuna, Tena, Ecuador.

${ }^{2}$ Grupo de Investigación en Biogeografía y Ecología Espacial (BioGeoE²), Universidad Regional Amazónica Ikiam, 7 km vía Muyuna, Tena, Ecuador

${ }^{3}$ Universidad San Francisco de Quito USFQ, Colegio de Ciencias Biológicas y Ambientales, Instituto de Biodiversidad Tropical iBIOTROP, Museo de Zoología y Laboratorio de Zoología Terrestre, Quito 170901, Ecuador.

${ }^{4}$ Instituto Nacional de Biodiversidad, calle Rumipamba 341 y Av. de los Shyris, Casilla 17-078976, Quito, Ecuador.

Corresponding Author: Biogeography and Spatial Ecology Research Group, Faculty of Life Sciences, Universidad Regional Amazónica Ikiam

H. Mauricio Ortega-Andrade ${ }^{2,4}$

Km 7 road to Muyuna, Tena, Napo Province, Ecuador.

Email address: mauricio.ortega@ikiam.edu.ec

\section{Abstract}

We report the rediscovery of Laura's Glassfrog, Nymphargus laurae Cisneros-Heredia and McDiarmid, 2007, based on two specimens collected at the Colonso-Chalupas Biological Reserve, province of Napo, Ecuador. The species was described and known from a single male specimen collected in 1955 at Loreto, north-eastern Andean foothills of Ecuador. Limited information was available about the colouration, systematics, ecology, and biogeography of $N$. laurae. We provide new data on the external morphology, colouration, distribution and comment on its conservation status and extinction risk. We discuss the phylogenetic relationships of $N$. laurae, which forms a clade together with $N$. siren and $N$. humboldti. The importance of research in unexplored areas must be a national priority to document the biodiversity associated, especially in protected areas.

Key words: Phylogeny, taxonomy, glassfrogs, Colonso-Chalupas Biological Reserve, systematics.

\section{Introduction}


Nymphargus Cisneros-Heredia \& McDiarmid, 2007 currently includes 42 described species of glassfrogs (family Centrolenidae), and 21 of them occur in Ecuador (Guayasamin et al., 2020; Frost, 2021). Despite increasing efforts to better understand the diversity, natural history, ecology and distribution of glassfrogs in the tropical Andes, several species of Nymphargus remain known only from their type localities or few collected specimens [e.g., Nymphargus buenaventura Cisneros-Heredia \& Yanez-Muñoz, 2007 (Cisneros-Heredia \& Yánez-Muñoz, 2007; Yánez-Muñoz et al., 2014), N. laurae Cisneros-Heredia \& McDiarmid 2007 (CisnerosHeredia \& McDiarmid, 2007), N. lindae Guayasamin in Guayasamin et al. 2020 (Guayasamin et al., 2020), N. manduriacu Guayasamin, Cisneros-Heredia, Vieira, Kohn, Gavilanes, Lynch, Hamilton, and Maynard, 2019 (Guayasamin et al., 2019)].

Laura's Glassfrog Nymphargus laurae was described based on a male specimen collected in 1955 at Loreto, on the north-eastern foothills of the Andes of Ecuador (Cisneros-Heredia \& McDiarmid, 2007). More than 60 years have passed since the collection of the holotype and single known specimen of $N$. laurae, and no additional individuals or information has become available for the species (Guayasamin et al., 2020). Since its description, numerous herpetologists have searched for $N$. laurae along the eastern slopes of the Andes of Ecuador without success. Due to its apparent rarity, restricted distribution, and extensive habitat change and loss at the type-locality, $N$. laurae was classified as Endangered at the national level (OrtegaAndrade et al., 2021) and Critically Endangered at the global level (Cisneros-Heredia, 2008)

Between 2016-2018, we collected two individuals of Nymphargus laurae at the ColonsoChalupas Biological Reserve. Based in this findings, we provide new information about the morphological and chromatic variation, natural history, conservation status and extinction risk and reveal for the first time the phylogenetic position of $N$. laurae in Centrolenidae.

\section{Materials \& Methods}

\section{Study area and field surveys}

The Colonso-Chalupas Biological Reserve is a national protected area located on the foothills of the north-eastern Andes of Ecuador, in the province of Napo. This biological reserve protects $932.46 \mathrm{~km}^{2}$, extending between $560-4432 \mathrm{~m}$ elevation and being home to a variety of ecosystems, from tropical evergreen forests to paramos (van der Hoek et al., 2018). It is part of an ecological corridor with two neighbouring protected areas: Antisana Ecological Reserve, to the north, and Llanganates National Park, to the south (Ramis et al., 2018; van der Hoek et al., 2018). Montane evergreen cloud forests in Colonso-Chalupas are characterised by a great variety of trees of the families Melastomataceae, Solanaceae, Myrsinaceae, Aquifoliaceae, Araliaceae, Rubiaceae. Those trees reach up to $15-25 \mathrm{~m}$ in height, showing gnarled trunks and branches, and dense and compact crowns covered by epiphytes, including orchids, bromeliads, aroids, and 
78 ferns (MAE, 2012, 2013). This ecosystem is usually covered by mist, either constantly or during 79 the early morning and late afternoon (Ramis et al., 2018). The average annual rainfall is 4620 $80 \mathrm{~mm}$, and the average annual temperature is $28.7^{\circ} \mathrm{C}$. The rainy season extends between March 81 and July, with $448 \mathrm{~mm}$ of monthly average rainfall and $23.5^{\circ} \mathrm{C}$ of monthly average temperature. 82 The dry season is between August and January, with $353 \mathrm{~mm}$ of average monthly precipitation 83 and $23.9^{\circ} \mathrm{C}$ of average monthly temperature (INAMHI, 2015). Nocturnal surveys for collection 84 of amphibians and reptiles were conducted at the Colonso-Chalupas Biological Reserve from $8519 \mathrm{~h} 00-02 \mathrm{~h} 00$, at a stream nearby to Ikiam's Scientific Station, on 17 October $2016\left(0.9348^{\circ} \mathrm{S}\right.$ $\left.8677.9270^{\circ} \mathrm{W}, 1506 \mathrm{~m}\right)$ and at the Narpa stream, on 09 June $2018\left(0.9353^{\circ} \mathrm{S} 77.9268^{\circ} \mathrm{W}, 1440 \mathrm{~m}\right)$

87 (Fig. 1). Environmental Ministry of Ecuador provided full approval for this research (MAE88 DNB-CM-2017-0062). Specimens are deposited in the herpetological collection of the Instituto 89 Nacional de Biodiversidad (Quito, Ecuador).

\section{Morphological characteristics}

Terminology, characters and measurements follow formats and definitions described by Cisneros-Heredia \& McDiarmid, 2007, Watters et al. (2016) and Guayasamin et al. (2020). Examined frogs were photographed in life, anaesthetised with lidocaine 2\%; specimens and tissues were fixed in $96 \%$ ethanol and preserved separately in $75 \%$ ethanol. Sex and maturity were determined by directly examining gonads through dissections and noting secondary sexual characters (i.e., vocal slits and nuptial pads). Colour patterns are based on photographs and annotations of living specimens taken in the field. Adjective "enamelled" is used to describe the shiny white colouration produced by the accumulation of iridophores (Lynch \& Duellman, 1973; Cisneros-Heredia \& McDiarmid, 2007).

The following measurements were taken with a digital calliper $(0.02 \mathrm{~mm}$ accuracy, rounded to nearest $0.1 \mathrm{~mm}$ ) under a stereomicroscope: snout-vent length (SVL); head width (HW); head length (HL), snout length (SL); interorbital distance (IOD), horizontal eye diameter (ED), internarial distance (IND), eye-nostril distance (EN), horizontal tympanum diameter (TD); upper eyelid width (UEW), forearm length (FLL), hand length (HAL), finger IV disk width (Fin4DW), thigh length (THL), tibia length (TL), foot length (FL).

Morphological data used for comparisons were obtained from direct examination of specimens deposited in the following collections: The Natural History Museum, Department of Zoology, London (BMNH); División de Herpetología, Instituto Nacional de Biodiversidad, Quito (DHMECN); Instituto de Ciencias Naturales, Universidad Nacional de Colombia, Bogotá (ICN);

114 Zoology, Harvard University, Cambridge, MA (MCZ); Museo de Zoología, Pontificia 115 Universidad Católica del Ecuador, Quito (QCAZ); National Museum of Natural History, 116 Smithsonian Institution, Washington, D.C. (USNM); Museo de Zoología, Universidad San 117 Francisco de Quito, Quito (ZSFQ). 
119 DNA extraction, amplification, sequencing, and phylogenetic analyses

120 Genomic DNA was extracted from hepatic tissue preserved in $96 \%$ ethanol from specimen

121 DHMECN 15383, using the "Isolation of Genomic DNA" protocol, Wizard Genomic DNA

122 Purification Kit (Promega, 2019). Three mitochondrial gene fragments [12S ribosomal rRNA

123 gene, 16S ribosomal rRNA gene, Cytochrome C Oxidase Subunit 1 (COI)], and one nuclear gene

124 [Recombination Activating Protein 1 gene (RAG1)] were amplified using the Polymerase Chain

125 Reaction (Saiki et al., 1988). Primers for 12S gene (12S H10-FWR 5'-

126 CACYTTCCRGTRCRYTTACCRTGTTACGACTT-3' / 12S L4E-REV 5'-

127 TACACATGCAAGTYTCCGC-3'), 16S gene (16Sar-L-FWR 5'-

128 CGCCTGTTTATCAAAAACAT-3' / 16Sbr-H-REV 5'-CCGGTCTGAACTCAGATCACGT-

129 3'), COI (dgLCO-1490-FWR 5'-GGTCAACAAATCATAAAGAYATYGG-3' / dgHCO-2198-

130 REV 5'-TAAACTTCAGGGTGACCAAARAAYCA-3') and RAG1 (RAG1-R182

131 5'GCCATAACTGCTGGAGCATYAT3' / RAG1-R270

132 5'AGYAGATGTTGCCTGGGTCTTC3'), were used (Heinicke et al, 2007). Each PCR reaction

133 was composed of a $25 \mu \mathrm{l}$ reaction mix containing: $12.5 \mu \mathrm{l}$ GoTaq Green Master Mix, $4.5 \mu 1 \mathrm{H}_{2} 0$,

$1341 \mu \mathrm{l}$ on $10 \mu \mathrm{M}$ of Forward primer and $1 \mu \mathrm{l}$ on $10 \mu \mathrm{M}$ Reverse primer, and $5 \mu$ l of genomic DNA.

135 We perform amplifications on an Applied Biosystems GeneAmp PCR System 9700 thermal

136 cycler. The amplification program for $12 \mathrm{~S}$ primers was set with an initial denaturation of $94^{\circ} \mathrm{C}(5$

$137 \mathrm{~min})$ followed by 38 cycles of $94^{\circ} \mathrm{C}(30 \mathrm{sec}), 49^{\circ} \mathrm{C}(30 \mathrm{sec}), 72^{\circ} \mathrm{C}(1 \mathrm{~min})$, with a final extension

138 temperature of $72^{\circ} \mathrm{C}(7 \mathrm{~min})$ and $4^{\circ} \mathrm{C}$ for an unlimited period; for $16 \mathrm{~S}$ primers was set with an

139 initial denaturation of $95^{\circ} \mathrm{C}(5 \mathrm{~min})$ followed by 30 cycles of $95^{\circ} \mathrm{C}(30 \mathrm{sec}), 57^{\circ} \mathrm{C}(30 \mathrm{sec}), 72^{\circ} \mathrm{C}$

140 (45 sec), with a final extension temperature of $72^{\circ} \mathrm{C}(5 \mathrm{~min})$ and $4{ }^{\circ} \mathrm{C}$ for an unlimited period; for

$141 \mathrm{COI}$ primers was set with an initial denaturation of $95^{\circ} \mathrm{C}(5 \mathrm{~min})$ followed by 30 cycles of $95^{\circ} \mathrm{C}$

$142(30 \mathrm{sec}), 48^{\circ} \mathrm{C}(30 \mathrm{sec}), 72^{\circ} \mathrm{C}(45 \mathrm{sec})$, with a final extension temperature of $72^{\circ} \mathrm{C}(5 \mathrm{~min})$ and

$1434^{\circ} \mathrm{C}$ for an unlimited period; and for RAG1 primers was set with an initial denaturation of $94^{\circ} \mathrm{C}$

144 (5 min) followed by 38 cycles of $94^{\circ} \mathrm{C}(30 \mathrm{sec}), 52^{\circ} \mathrm{C}(30 \mathrm{sec}), 72^{\circ} \mathrm{C}(1 \mathrm{~min})$, with a final

145 extension temperature of $72^{\circ} \mathrm{C}(7 \mathrm{~min})$ and $4^{\circ} \mathrm{C}$ for an unlimited period. Amplified DNA

146 products were visualised by electrophoresis on a $\%$ agarose gel and post-staining with

147 Tris/Borate/EDTA buffer (TBE) under blue light. PCR-amplified products were purified using

148 Illustra $^{\mathrm{TM}}$ ExoProStar ${ }^{\mathrm{TM}}$ Enzymatic PCR and Sequencing Clean-Up Kit. Sequencing was

149 performed in both DNA strain directions and undertaken by Macrogen, Seoul, South Korea

150 (http://www.macrogen.com). Chromatographs resulting from sequencing were revised and edited

151 using Geneious Prime v.2020.0.5 software (Kearse et al., 2012). New sequences were deposited

152 in GenBank with the following accession numbers: 12S: MZ820691; 16S: MZ831508; COI:

153 MZ828399; RAG1: MZ835991).

154

155 To infer the phylogenetic position of Nymphargus laurae, we included sequences for 119 species

156 (Table S1) selected from Guayasamin et al. (2020), obtained from the NCBI GenBank database

157 (National Center for Biotechnology Information NCBI, 2020). We included two species for 
158 Allophrynidae, a sister lineage of Centrolenidae, as outgroups (Table S1) and rooted the

159 phylogeny with Allophryne ruthveni. Alignments were reviewed and edited manually to remove

160 regions with a high proportion of missing data at the edges and hypervariable regions with

161 Geneious Prime v.2020.0.5 software (Kearse et al., 2012). Highly variable regions into the

162 alignments are subject to the accumulation of gaps caused by deletions, insertions and

163 substitution mutation, commonly identified to contributed to the inaccuracy of phylogenetic

164 inference (Dwivedi \& Gadagkar, 2009). We used Mesquite v3.61 software (Maddison \&

165 Maddison, 2019) to store the sequences and to create a concatenated matrix of all genes (12S,

$16616 \mathrm{~S}, \mathrm{COI}$ and RAG1). Because our combined data set comprised two ribosomal genes (12S and

167 16S), one protein-coding mitochondrial gene (COI) and one nuclear gene (RAG1), we tested a

168 matrix with 8 partitions with PartitionFinder2 v2.1.1 (Lanfear et al., 2012), in the CIPRES

169 Science Gateway V.3.3 (Miller, Pfeiffer \& Schwartz, 2010). This process resulted in the

170 selection of GTR + I + G as the optimal model for nucleotide substitution for all partitions.

171

172

Phylogenetic analyses were conducted using Maximum Likelihood (ML) and Bayesian Methods

173 (BA) on the aligned matrix in the CIPRES Science Gateway V.3.3. ML analyses were performed using Garli v2.0 [Genetic Algorithm for Rapid Likelihood Inference; (Zwick1, 2006)]. We

175 perform a total of 10 runs to reduce the probability of inferring a suboptimal solution; all the other settings were set on default. Node support was evaluated using 1000 bootstrap pseudoreplicates. Bayesian phylogenetic analyses were performed in MrBayes v3.2.2 (Ronquist \& Huelsenbeck, 2003), using five runs of the Monte Carlo Markov Chain (MCMC) algorithm for 20 million generations each, with four heated chains ( 0.2 heating parameter). Trees were sampled every 20000 generations, with burning of $25 \%$ of the total trees. To evaluate the effective sampling size of the five independent, uncorrelated runs, we used the statistical number of effectively independent draws from the posterior (ESS > 200) visualised with Tracer v1.6.

183 (Rambaut et al., 2013). Phylogenetic trees were edited using FigTree v1.4.2. (Rambaut, 2014).

184

\section{Conservation Status}

186 We assessed the conservation status of Nymphargus laurae based on an environmental risk surface model $(0=$ no threats, $1=$ maximum threat value $)$ produced for Ecuadorian amphibians by (Ortega-Andrade et al., 2021), a satellite image (2019, Google Earth) from the type locality of the species, and a map of the National System of Protected Areas

190 (http://ide.ambiente.gob.ec/mapainteractivo/). We classify the extinction risk of $N$. laurae based

191 on the categories and criteria presented by $\operatorname{IUCN}(2012,2019)$.

192

193

\section{Results}

194

195 Surveys at the Colonso-Chalupas Biological Reserve resulted in the collection of two specimens

196 of Nymphargus laurae. A subadult female (DHMECN 15383) was found at a stream near the

197 Ikiam's Scientific Station on 17 October 2016 by H. Mauricio Ortega-Andrade. An adult male 
198 (DHMECN 15384) was collected at Narpa stream, on 09 June 2018 by Miguel Gómez Laporta

199

200

201

202

203

204

205

206

207

208

209

210

211

212

213

214

215

216

217

218

219

220

221

222

223

224

225

226

227

228

229

230

231

232

233

234

235

236

237

and $\mathrm{H}$. Mauricio Ortega-Andrade. Both specimens were found active on leaves of riverine vegetation up to 4.5 meters, next to small creeks, at night between 22h00-23h00. Nymphargus laurae was found in syntopy with $N$. cochranae, Pristimantis quaquaversus, $P$. malli, $P$. incomptus, $P$. ventrimarmoratus, $P$. aff. petersi, and $P$. aff. conspicillatus. The female was classified as subadult by having unconvoluted oviducts and immature ovarian eggs.

Both specimens are very similar to the holotype in their anatomy and colouration, showing all diagnostic characters described for Nymphargus laurae: (1) vomerine teeth absent; (2) snout truncated in dorsal and lateral views; (3) tympanic annulus evident; (4) dorsal skin shagreen with slightly elevated warts corresponding to ocelli and scattered spicules, (5) ventral skin granular, without cloacal ornamentation except for a pair of large flat tubercles; (6) parietal peritoneum white, covering $2 / 3$ of the abdomen; all other peritonea clear; (7) liver lobed, hepatic peritoneum clear; (8) humeral spine absent; (9) basal webbing between fingers I, II and III, outer fingers III 2 $2 / 3-2 \frac{1}{3} \mathrm{IV} ;(10)$ webbing on feet similar to holotype (see below); (11) no dermal folds or tubercles on hands, arms, feet or tarsi; (12) unpigmented nuptial pad Type-I, concealed prepollex; (13) Finger II longer than Finger I; (14) eye diameter larger than the width of disc on Finger III; (15) colouration in life, green with ocelli (yellow spots surrounded by black), and in preservative, lavender with ocelli (cream-coloured centre surrounded by dark lavender).

The new specimens show no relevant differences with the holotype, and observed differences fall within known intraspecific variation found also between specimens of other congeneric species. The male specimen (DHEMCN 15384) has SVL $=22.1 \mathrm{~mm}$, slightly larger than the male holotype (USNM 288453, $19.9 \mathrm{~mm}$ SVL), and both are smaller than the subadult female (DHMECN 15383, $22.3 \mathrm{~mm} \mathrm{SVL}$ ). Differences in measurements and proportions between these males are probably due to intraspecific variation (Table 1). The male has a combination of large and small spicules (visible under magnification) on the head, dorsum, and flanks, but spicules on the lower part of dorsum and eyelids are smaller. The female has smaller spicules compared to the male on the head, dorsum and flanks. A spicule is present in the centre of each ocellus, being more prominent and pointed when compared to other body spicules. The female has the tympanic annulus proportionally more covered by the supratympanic fold than in males. Hand webbing in the new specimens (basal webbing between fingers I, II and III, outer fingers III $2 \frac{2}{3}$ $-21 / 3$ IV; Fig. 2A) is very similar to the holotype (III $2 \frac{2}{3}-2 \frac{1}{2}$ IV), and feet webbing shows slight variation: I $2-23 / 4$ II $1 \frac{1}{2}-23 / 4$ III $1 \frac{1 / 2}{2}-23 / 4$ IV $23 / 4-1 \frac{1}{2}$ V in the female and I $23 / 4-2$ $3 / 4$ II $1 \frac{1 / 2}{2}-23 / 4$ III $1 \frac{1 / 2}{2}-23 / 4$ IV $2 \frac{1}{2}-13 / 4$ V in the male (Fig. 2B) (I $2^{-}-2^{+}$II $1 \frac{1}{2}-2^{+}$III $1^{+}-2 \frac{1}{2}$ IV $2 \frac{1}{2}-1 \frac{1}{2} \mathrm{~V}$ in the male holotype). The male (DHMECN 15384) has two papillae on discs of Toe I and II (Fig. 2C). The female (DHMECN 15383) lacks papillae on toes. The holotype of $N$. laurae has two papillae on each toe disc, except for Toe V.

In preservation, the new specimens show similar colourations to the holotype. However, the female shows a lavender dorsum, while the new male and the holotype have cream dorsum with

Peer] reviewing PDF | (2021:10:66680:1:0:NEW 21 Nov 2021) 
238 lavender tones. The female has 19 ocelli on the body and eight on the head (Fig. 3A), and the 239 male has six ocelli on the body and three on the head (Fig. 3B) (14 on the body and five on the head of the holotype). Upper eyelids are dark lavender. Fingers and toes lack melanophores. All ventral surfaces are cream. The parietal peritoneum and sclera are white, covering $2 / 3$ of the abdomen; pericardium, digestive peritonea, hepatic peritoneum, and urogenital peritonea are clear.

The colouration in life of Nymphargus laurae remains known only from the brief description provided by Gustavo Orcés-Villagómez, Ecuadorian zoologists who donated the specimen to James A. Peters, USNM curator, and reported in the original description of the species: "green with yellow spots surrounded by black" (Cisneros-Heredia and McDiarmid 2007). The new specimens allow for a complete description: Head green, darker than the body, lip greenish cream; dorsal surfaces of body, arms and legs green; ocelli on head and body having yellow spots surrounded by black; ocelli absent on arms and legs; upper flanks coloured as dorsum but lower flanks cream, with a sharp division between both; hands, finger, feet and toes yellowishgreen, with yellow discs; nuptial pad cream (Fig. 4). Throat greenish-white, all other ventral surfaces cream white. Yellow circumpupillary ring and whitish iris with thin dark reticulations and dark flecks concentrated towards the middle (Fig. 4). Nictitating membrane yellowish, without reticulations. Green bones.

We reconstructed the evolutionary tree (Fig. 5) of Nymphargus laurae with a dataset including 120 taxa and 2823 nucleotides (in the aligned matrix). ML and BA analyses are both congruent and recovered the phylogenetic position of $N$. laurae as sister species of $N$. siren and both forming a clade sister to $N$. humboldti. The clade $N$. laurae $+N$. siren $+N$. humboldti has low BA posterior probability $(<0.9$ node value in Fig. 5$)$, while the ML bootstrap value has relative high support (0.7 node value in Fig. S1). This clade is closely related to $N$. megacheirus and $N$. anomalus (Fig. 5). Phylogenetic relationships among major groups to genus level are supported with high values, in Hyalinobatrachium, Centrolene, Cochranella, Espadarana, Rulyrana, Sachatamia, Teratohyla, and Vitreorana (Fig. S1).

Nymphargus laurae is known from two localities in the province of Napo, on the north-eastern flanks of the Andes of Ecuador, at elevations between 700-1500 m (Fig. 1). The type locality, Loreto, was originally covered by lowland evergreen forests, and it is located on the lower slopes of the Sumaco volcano, on the upper Napo valley. Satellite images (Fig. 1) show that less than $10 \%$ of the natural forests remains at the type locality. The new locality, Colonso-Chalupas, is still covered by evergreen montane forest (Fig. 1). The environmental risk surface (ERS) results

273 in threat values from 0 (Colonso-Chalupas) to 0.37 (Loreto), due to habitat loss and fragmentation for cattle raising and agriculture, deforestation, roads, oil pipelines, and stochastic

275 events related with explosions of the Sumaco Volcano.

276

277 Discussion 
278 The records of Nymphargus laurae presented in this paper correspond to the first report of the 279 species after 66 years from its original collection. The Colonso-Chalupas Biological Reserve is 280 the second known locality of $N$. laurae, extending its geographic range in ca. $77 \mathrm{~km} \mathrm{SW}$ from the 281 type locality, at Loreto, province of Orellana, Ecuador (Cisneros-Heredia \& McDiarmid, 2007).

282 These records also extend the altitudinal range of the species from ca. $700 \mathrm{~m}$ (see comments on 283 the elevation of Loreto by Urgilés et al. 2017 up to $1500 \mathrm{~m}$. Despite the altitudinal difference, 284 both localities are in the same biogeographic region and watershed, and no significant

285 biogeographic barriers separate them. Nymphargus laurae maybe more widespread than 286 currently known, but possibly it is endemic to north-eastern Ecuador.

287

Dorsal colouration pattern showing ocelli with yellow centre surrounded by black on a green dorsum is shared by three ocellated glassfrogs: N. cochranae, N. laurae and N. lindae. These species share a common biogeographic pattern across the eastern Andean slopes in Ecuador, with $N$. cochranae being widespread across the eastern Andean slopes of the Andes of Ecuador and southern Colombia and sympatric with N. laurae (Cisneros Heredia \& McDiarmid, 2005; 2006; 2007, this paper). All three species are very similar in their morphology and colouration, and when a single known specimen was available for $N$. laurae, the differentiation between this species and $N$. lindae was weak and it was suggested that $N$. cochranae and $N$. laurae may be synonyms (Guayasamin et al. 2020). Now we can provide strong evidence for the distinctiveness of $N$. laurae, which is not closely related to $N$. cochranae nor $N$. lindae, based on morphological, chromatic, and molecular data. Externally, $N$. laurae differs from $N$. cochranae by having much larger ocelli (ocelli in N. cochranae are small, and in some specimens they are so small that without close inspection, they appear to be just dark spots); ocelli with yellow centre (orange centre in N. cochranae), Finger II longer than Finger I (Figer I > Finger II in N. cochranae); distal subarticular tubercle of fourth finger bifurcate; indistinct outer metatarsal tubercle; supernumerary tubercles present; no ocelli on forearms and shanks (present in some $N$. cochranae); no vomerine teeth (present in some $N$. cochranae); and smaller body size (23.8-31.6 $\mathrm{mm}$ SVL in males of $N$. cochranae vs. 19.9-22.3 mm SVL in males of $N$. laurae). Nymphargus laurae and $N$. lindae are very similar, but $N$. lindae is diagnosable due to the present of vomerine teeth (absent in $N$. laurae), low ulnar and tarsal folds present (absent in $N$. laurae), and slightly larger body size (19.9-22.3 mm SVL in males of $N$. laurae vs. 23.0-26.5 mm SVL in males of $N$. lindae). The condition of the papillae at the tip of toes was used as a diagnostic character in the original description of $N$. lindae, but it is not a useful taxonomic character due to its variation in $N$. laurae. Absence of papillae in the female and in some toes in the new male of $N$. laurae

312 (Fig. 2B) suggest that papillae show intraspecific variation or is of external origin. The presence

313 of papillae on toes discs was not used as a diagnostic character in the original description of $N$.

314 laurae Cisneros-Heredia and McDiarmid (2007) actually noted that intraspecific variation was

315 observed in the presence/absence of papillae on toe discs of other congeneric species (i.e.,

316 Nymphargus ignotus). We have seen similar papillae in some specimens of Chimerella,

317 Vitreorana and Espadarana, showing intraspecific variation (e.g., Espadarana prosoblepon, 
318 Vitreorana ritae).

319

320

Phylogenetic analyses place Nymphargus laurae in a clade with $N$. siren and N. humboldti (Fig.

321

5). These results are interesting due to the colouration differences among $N$. laurae, $N$. humboldti

322 and $N$. siren and their close distribution in nearby areas at the Sumaco volcano and the

323 Guacamayos mountain range. Nymphargus siren and $N$. humboldti are almost identical, the only

324 phenotypic diagnostic character being the smaller body size of $N$. siren. However, our

325 phylogenetic information shows that, despite their similarities, they are not sister to each other. Nymphargus siren is distributed on the eastern Andean slopes from southern Colombia to northern Ecuador, at elevations between 1410-2000 m; N. humboldti, is known from two localities on the eastern Andean slopes of central Ecuador, at elevations between 1770-2400 m (Guayasamin et al., 2020); and N. laurae is restricted to lowland and foothill forests along the Upper Napo River basin (Cisneros-Heredia and McDiarmid 2007, this paper). Our results suggest the dispersal of this clade occurred in the northern Andes, along montane forest in the upper Napo River basin, Guacamayos mountain range and Sumaco volcano (Fig. 1A). Although these species have similar elevations and distributional ranges, the role of morphological, behavioural, bioacoustics and physiological features (i.e., climatic tolerances) is still intriguing, regarding their evolution and biogeographical diversification in eastern Andes of Ecuador.

Based on data provided herein, we propose the following extinction risk assessment for Nymphargus laurae: (1) N. laurae has suffered population reductions, based on the continuous decline in habitat quality at its type locality and surroundings, where no recent record for the species have been obtained despite surveys. Habitat quality at Colonso-Chalupas is better by being part of a protected area. However, since only three specimens are known for the species, we refrain from using criterion A until more data are available to at least inferred the population status of the species; (2) the species is known from just two localities with different conservation conditions, thus each one should be evaluated as a different threat-defined location; (3) an EOO cannot be estimated with two localities but the estimated AOO is $8 \mathrm{~km}^{2}$, which is within the threshold for Critically Endangered $\left(<10 \mathrm{~km}^{2}\right)$. However, we consider that it is possible that the geographic range of $N$. laurae is larger, closer to the threshold for Endangered $\left(10-500 \mathrm{~km}^{2}\right)$ under criterion B2; (4) the type locality and any potential locality outside of Colonso-Chalupas are under ongoing habitat decline due to forest loss and water pollution. This information suggests the extinction risk of $N$. laurae is relatively high and we propose that it should be classified under the IUCN category of Endangered (EN) based on criteria B2ab(iii,iv). Although $N$. laurae now is expected to have a wider distribution, urgent conservation actions are encouraged for this species and other range-restricted amphibians the eastern Andes slopes of Ecuador.

\section{Conclusions}


358 We provide new information about Nymphargus laurae, a species previously known from a 359 single specimen collected decades ago. Our new specimens collected at the Colonso-Chalupas

360 Biological Reserve increase the geographic range of the species along the north-eastern slopes of

361 the Ecuadorian Andes. New insights into the morphology, colouration, and phylogeny of $N$.

362 laurae demonstrate its distinctiveness among other ocellated glassfrogs, with which it is not

363 closely related because it is part of a clade with $N$. siren and $N$. humboldti. Although now known

364 from a second locality, the geographic range of $N$. laurae is still limited and habitat loss and

365 fragmentation are threatening the long-term survival of populations outside of protected areas,

366 thus we suggest that the species' extinction risk should be categorised as Endangered at the

367 global and national level and conservation actions are urgently encouraged. The importance of

368 research in unexplored areas must be a national priority to document the biodiversity associated,

369 especially for range-restricted species and in little-explored protected areas.

370

371

372

373

374

375

376

377

378

379

380

381

382

383

384

385

386

387

388

389

390

391

392

393

394

\section{Acknowledgements}

We thank Miguel Gómez-Laporta, Michelle Guachamin, and Jimmy Velasteguí for field companion and support; Andrea Carrera for provide support for the molecular labwork; and the reviewers for their comments. We are grateful to the following people and institutions who provided access to specimens: Jeff Streicher, David Gower and Mark Wilkinson (BMNH), Mario Yánez-Muñoz (DHMECN), John D. Lynch (ICN), Linda Trueb, William E. Duellman and John E. Simmons (KU), James Hanken and Jose Rosado (MCZ), Santiago Ron (QCAZ), George Zug, Roy McDiarmid and Ron Heyer (USNM), and Carolina Reyes-Puig and Emilia Peñaherrera (ZSFQ). New specimens of $N$. laurae were collected as part of the project "On the quest of the golden fleece in Amazonia: The first herpetological DNA - barcoding expedition to unexplored areas on the Napo watershed, Ecuador", funded by the Secretaría Nacional de Ciencia y Tecnología del Ecuador (Senescyt-ENSAMBLE Grant \#PIC-17-BENS-001), and The World Academy of Sciences (TWAS Grant \#16-095, granted to HMOA). Research by DFCH was supported by the Smithsonian Women's Committee, Smithsonian Institution (2002 Research Training Program, National Museum of Natural History), World Wildlife Fund (WWF-EFN, Russel E. Train Education for Nature Program), Secretaría de Educación Superior, Ciencia, Tecnología e Innovación (SENESCYT, Programa "Becas de Excelencia"), Universidad San Francisco de Quito (Chancellor grants, COCIBA grants, Collaboration grants, projects HUBI ID 34, 36, 39, 48, 1057, 7703, 12253, 13524), and "Proyecto Descubre Napo", an initiative of Universidad San Francisco de Quito in association with Wildlife Conservation Society and funded by the Gordon and Betty Moore Foundation as part of the project: WCS Consolidating Conservation of Critical Landscapes (mosaics) in the Andes.

\section{5 \\ References}

Cisneros-Heredia DF. 2008. Nymphargus laurae. The IUCN Red List of Threatened Species 2008: 
https://dx.doi.org/10.2305/IUCN.UK.2008.RLTS.T135996A4223953.en.

399 Cisneros-Heredia DF, McDiarmid RW. 2005. Amphibia, Centrolenidae, Centrolene peristictum, 400 Centrolene prosoblepon, Cochranella cochranae, Cochranella midas, Cochranella 401 resplendens, Cochranella spinosa, Hyalinobatrachium munozorum: Range extensions and

403

404

405

406

407

408

409

410

411

412

413

414

415

416

417

418

419 new provincial records. Check List 1:18-22.

Cisneros-Heredia DF, McDiarmid RW. 2006. A new species of the genus Centrolene (Amphibia: Anura: Centrolenidae) from Ecuador with comments on the taxonomy and biogeography of Glassfrogs. Zootaxa 1244:1-32.

Cisneros-Heredia DF, McDiarmid RW. 2007. Revision of the characters of Centrolenidae (Amphibia: Anura: Athesphatanura), with comments on its taxonomy and the description of new taxa of glassfrogs. Zootaxa 1572:1-82.

Cisneros-Heredia DF, Yánez-Muñoz MH. 2007. A new species of Glassfrog (Centrolenidae) from the southern Andean foothills on the west Ecuadorian region. South American Journal of Herpetology 2:1-10. $\quad$ DOI: https://doi.org/10.2994/18089798(2007)2[1:ANSOGC]2.0.CO;2.

Dwivedi B, Gadagkar SR. 2009. Phylogenetic inference under varying proportions of indelinduced alignment gaps. BMC Evolutionary Biology 9:1-18.

Frost DR. 2021.Amphibian Species of the World: an online reference. Version 6.1. Available at https://amphibiansoftheworld.amnh.org/index.php.

Guayasamin JM, Cisneros-Heredia DF, McDiarmid RW, Peña P, Hutter CR. 2020. Glassfrogs of Ecuador: Diversity, Evolution, and Conservation. Diversity 12:222. DOI: https://doi.org/10.3390/d12060222. 
420 Guayasamin JM, Cisneros-Heredia DF, Vieira J, Kohn S, Gavilanes G, Lynch RL, Hamilton PS, 421 Maynard RJ. 2019. A new glassfrog (Centrolenidae) from the Chocó-Andean Río 422

423 Heinicke MP, Duellman WE, Hedges SB. 2007. Major Caribbean and Central American frog 424 425 faunas originated by ancient oceanic dispersal. Proceedings of the National Academy of Sciences 104:10092-10097.

INAMHI. 2015. Anuario Meteorológico N52-2012.

427

428

436

IUCN. 2012. IUCN Red List categories and criteria. Gland and Cambridge: IUCN Species Survival Commission. version 3.1, second edition.

IUCN. 2019. Guidelines for Using the IUCN Red List Categories and Criteria IUCN. Species Survival Commission. version 14.

Kearse M, Moir R, Wilson A, Stones-Havas S, Cheung M, Sturrock S, Buxton S, Cooper A, Markowitz S, Duran C. 2012. Geneious Basic: an integrated and extendable desktop software platform for the organization and analysis of sequence data. Bioinformatics 28:1647-1649.

Lanfear R, Calcott B, Ho SY, Guindon S. 2012. PartitionFinder: combined selection of partitioning schemes and substitution models for phylogenetic analyses. Molecular Biology and Evolution 29:1695-1701.

Lynch JD, Duellman WE. 1973. A review of the centrolenid frogs of Ecuador, with descriptions of new species. Occasional Papers University of Kansas Museum of Natural History 16:166.

Maddison W, Maddison DR. 2019. Mesquite: a modular system for evolutionary analysis, ver. 3.61. http://mesquiteproject. org. 
443 Miller M, Pfeiffer W, Schwartz T. 2010. Creating the CIPRES Science Gateway for inference of 444 large phylogenetic trees. Gateway Computing Environments Workshop, 2010, 1-8.

445 Ministerio del Ambiente del Ecuador (MAE). 2012. Sistema de Clasificación de Ecosistemas del 446 Ecuador continental. Subsecretaría de Patrimonio Natural. Quito.

447 Ministerio del Ambiente del Ecuador (MAE). 2013. Sistema de Clasificación de Ecosistemas del 448 Ecuador Continental. Subsecretaría de Patrimonio Natural. Quito.

449 National Center for Biotechnology Information NCBI. 2020.GenBank. Bethesda (MD): National 450 Library of Medicine (US), National Center for Biotechnology Information. Available at https://www.ncbi.nlm.nih.gov/genbank/

452 453

Ortega-Andrade HM, Rodes Blanco M, Cisneros-Heredia DF, Guerra Arévalo N, López de Vargas-Machuca KG, Sánchez-Nivicela JC, Armijos-Ojeda D, Cáceres Andrade JF, Reyes-Puig C, Quezada Riera AB, Székely P, Rojas Soto OR, Székely D, Guayasamin JM, Siavichay Pesántez FR, Amador L, Betancourt R, Ramírez-Jaramillo SM, Timbe-Borja B, Gómez Laporta M, Webster Bernal JF, Oyagata Cachimuel LA, Chávez Jácome D, Posse V, Valle-Piñuela C, Padilla Jiménez D, Reyes-Puig JP, Terán-Valdez A, Coloma LA, Pérez Lara MaB, Carvajal-Endara S, Urgilés M, Yánez Muñoz MH. 2021. Red List assessment of amphibian species of Ecuador: A multidimensional approach for their conservation. PLOS ONE 16:e0251027. DOI: 10.1371/journal.pone.0251027.

Promega. 2019.Wizard ${ }^{\circledR}$ Genomic DNA Purification Kit Technical Manual. Available at https://worldwide.promega.com/resources/protocols/technical-manuals/0/wizardgenomic-dna-purification-kit-protocol/

Rambaut A. 2014.FigTree v1.4.2: Tree figure drawing tool. Available at http://tree.bio.ed.ac.uk/software/figtree/. 
466 Rambaut A, Suchard M, Xie D, Drummond A. 2013. Tracer 1.6. Edinburgh, UK: University of 467 Edinburgh.

468 Ramis L, Álvarez-Solas S, Peñuela M. 2018. Diagnóstico preliminar de la presencia de primates 469 que habitan el piedemonte de la Reserva Biológica Colonso-Chalupas. Revista de Investigación Talentos 5:1-11. DOI: https://doi.org/10.33789/talentos.5.78.

471

472

473

474

475

476

477

478

479

480

481

482

483

484

485

486

487

488

Ronquist F, Huelsenbeck JP. 2003. MrBayes 3: Bayesian phylogenetic inference under mixed models. Bioinformatics 19:1572-1574.

Saiki RK, Gelfand DH, Stoffel S, Scharf SJ, Higuchi R, Horn GT, Mullis KB, Erlich HA. 1988. Primer-directed enzymatic amplification of DNA with a thermostable DNA polymerase. Science 239:487-491.

Urgilés VL, Sanchez-Nivicela JC, Cisneros-Heredia DF. 2017. Notes on the distribution of Gastrotheca testudinea (Jiménez de la Espada, 1870) in Ecuador. PeerJ Preprints.

van der Hoek Y, Jensen R, Salagaje LA, Ordóñez Delgado L. 2018. A preliminary list of the birds of the foothills and south-eastern buffer zone of Colonso Chalupas Biological Reserve, Ecuador.

Watters JL, Cummings ST, Flanagan RL, Siler CD. 2016. Review of morphometric measurements used in anuran species descriptions and recommendations for a standardized approach. Zootaxa 4072:477-495. DOI: https://doi.org/10.11646/zootaxa.4072.4.6.

Yánez-Muñoz MH, Sánchez JC, López K, Rea E, Meza-Ramos PA, Oyagata LA, Guerrero P. 2014. Ampliaciones del rango de distribución de algunas especies de anfibios y reptiles en el suroccidente de Ecuador. Avances en Ciencias e Ingenierías 6:2-5. DOI: https://doi.org/10.18272/aci.v6i1.151.

Zwickl D. 2006. GARLI: genetic algorithm for rapid likelihood inference. See http://www. bio. 
Figure 1. (A) Map of Ecuador showing the distribution ranges of Nymphargus laurae: type locality (red star) and new locality (specimens INABIO15383-84; red dot), and phylogenetic sister species of $N$. laurae: $N$. siren (yellow dots) and $N$. humboldti (green dots). Interlined rectangle in A delimit the area shown in B. (B) Environmental risk surface (Ortega-Andrade et al., 2021) and protected areas in the distribution range of $N$. laurae. Numbers correspond to the following protected areas: (1) Cayambe-Coca National Park, (2) Sumaco-Napo-Galeras National Park, (3) Antisana Ecological Reserve, (4) Colonso-Chalupas Biological Reserve, (5) Llanganates National Park. Note high risk modelled for the type locality, which is excluded from the National System of Protected Areas of Ecuador. (C) Satellite image (2019, Google Earth) of the Upper Rio Napo valley, type locality near the town of Loreto (ca. $0.666670^{\circ} \mathrm{S}$, $77.316700^{\circ} \mathrm{W}$, ca. $500 \mathrm{~m}$ elevation), slopes of the Sumaco Volcano, on the Cordillera Oriental, eastern slopes of the Andes, Provincia de Orellana, República del Ecuador.

504

505

Figure 2. Hand (A), foot (B) and papillae (C) of Nymphargus laurae (INABIO15384). Tags and background color have been digitally removed.

507

Figure 3. Views of the body (dorsum and venter), of (A) the subadult female INABIO15383 and

509 (B) adult male INABIO15384 of Nymphargus laurae. Tags and background colour have been digitally removed.

511

512

Figure 4. Nymphargus laurae (INABIO15383), (A) dorsal view, (B) side view, (C) front view and (D) ventral view.

514

Figure 5. Optimal maximum likelihood tree (log likelihood $=-28155.635$ ) of Nymphargus (the clade including $N$. laurae is highlighted by an orange rectangle) inferred from concatenated DNA sequences of fragments of the mitochondrial genes $12 \mathrm{~S}, 16 \mathrm{~S}$, and COI, and the nuclear gen RAG1, totaling 2,823 aligned base pairs. Circles indicate significant support values for clades recovered by Bayesian (BA) and Likelihood (ML) analyses.

520

521

522

\section{Supplemental information}

524

Supplemental Table S1. Taxa and genetic markers used in this study.

526 Sequences generated in previous studies were downloaded from GenBank. Newly generated sequences are in bold blue. 
529 Supplemental Figure S1. Optimal maximum likelihood tree (log likelihood $=$-28155.635), 530 showing the phylogenetic relationships among 119 species of Centrolenidae and two outgroup 531 taxa. Values above nodes are posterior probabilities resulting from Bayesian phylogenetic 532 analyses (values $<0.9$ not shown, black circles $=1$ ). Numbers bellow nodes correspond to non533 parametric bootstraps (values $<0.70$ not shown, black circles $=1$ ). 


\section{Figure 1}

Figure 1

(A) Map of Ecuador showing the distribution ranges of Nymphargus laurae: type locality (red star) and new locality (specimens INABIO15383-84; red dot), and phylogenetic sister species of $N$. laurae: $N$. siren (yellow dots) and $N$. humboldti (green dots). Interlined rectangle in A delimit the area shown in B. (B) Environmental risk surface (Ortega-Andrade et al., 2021) and protected areas in the distribution range of $N$. laurae. Numbers correspond to the following protected areas: (1) Cayambe-Coca National Park, (2) Sumaco-Napo-Galeras National Park, (3) Antisana Ecological Reserve, (4) Colonso-Chalupas Biological Reserve, (5) Llanganates National Park. Note high risk modelled for the type locality, which is excluded from the National System of Protected Areas of Ecuador. (C) Satellite image (2019, Google Earth) of the Upper Rio Napo valley, type locality near the town of Loreto (ca. $0.666670^{\circ} \mathrm{S}$, $77.316700^{\circ} \mathrm{W}$, ca. $500 \mathrm{~m}$ elevation), slopes of the Sumaco Volcano, on the Cordillera Oriental, eastern slopes of the Andes, Provincia de Orellana, República del Ecuador. 


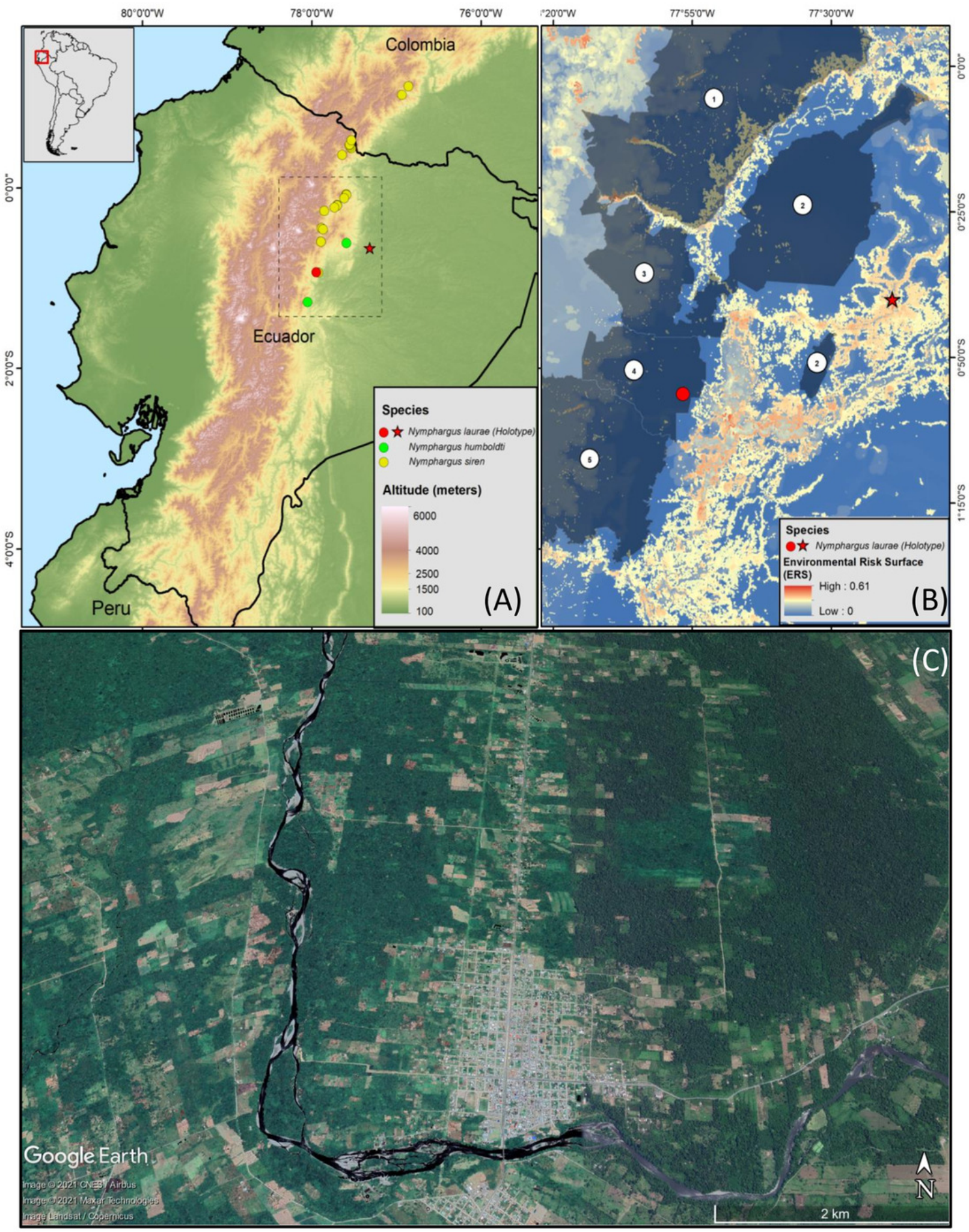




\section{Figure 2}

Figure 2

Hand (A), foot (B) and papillae (C) of Nymphargus laurae (INABIO15384). Tags and background color have been digitally removed.

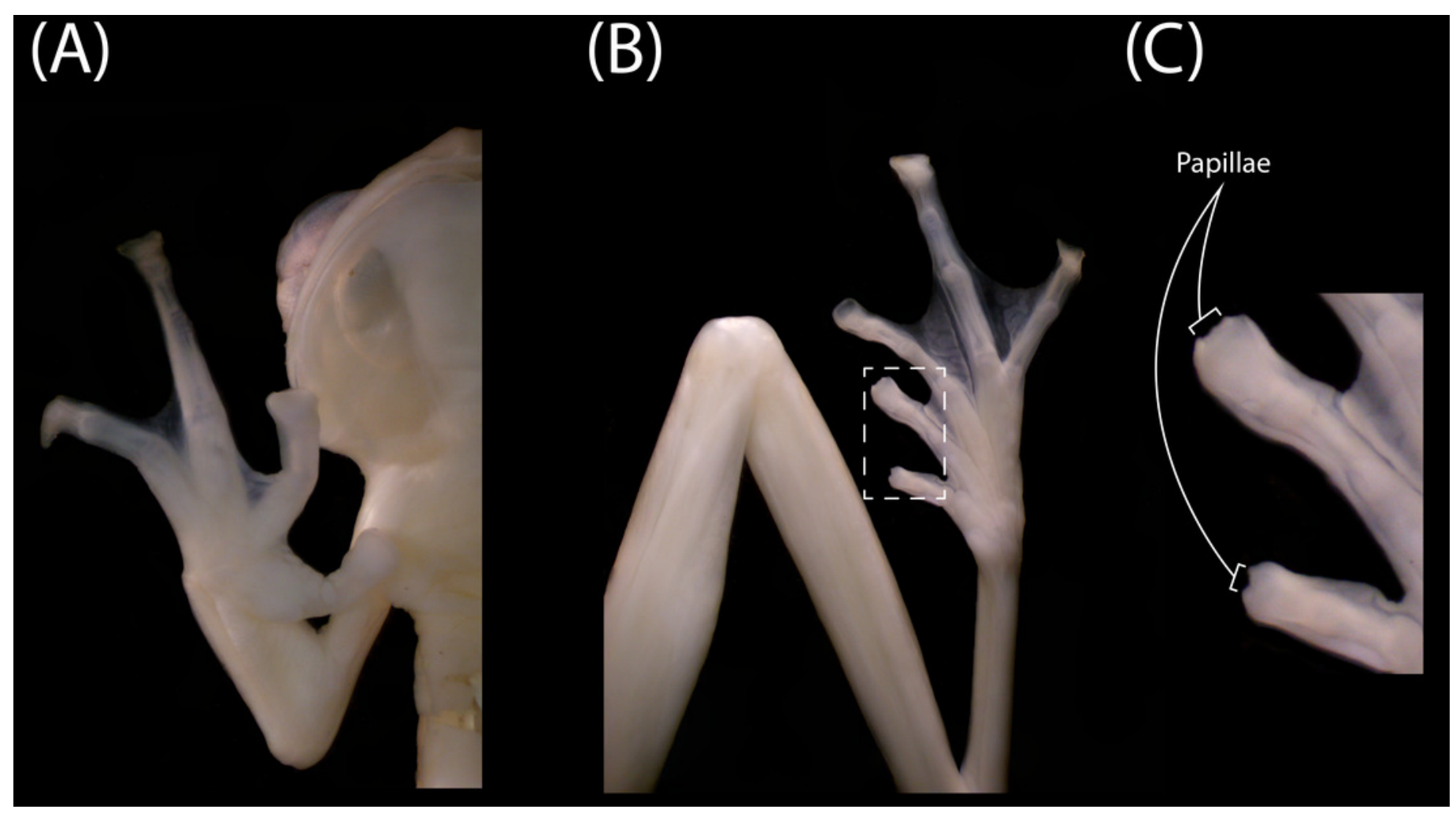




\section{Figure 3}

Figure 3

Views of the body (dorsum and venter), of (A) subadult female INABI015383 and (B) adult male INABIO15384 in specimens of Nymphargus laurae. Tags and background colour have been digitally removed. 
(A)

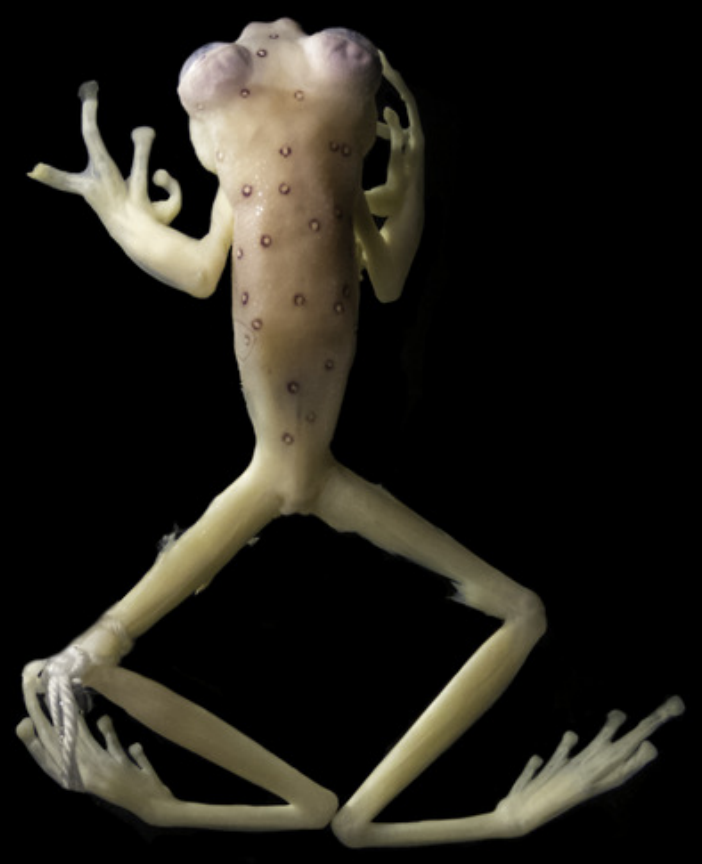

(B)

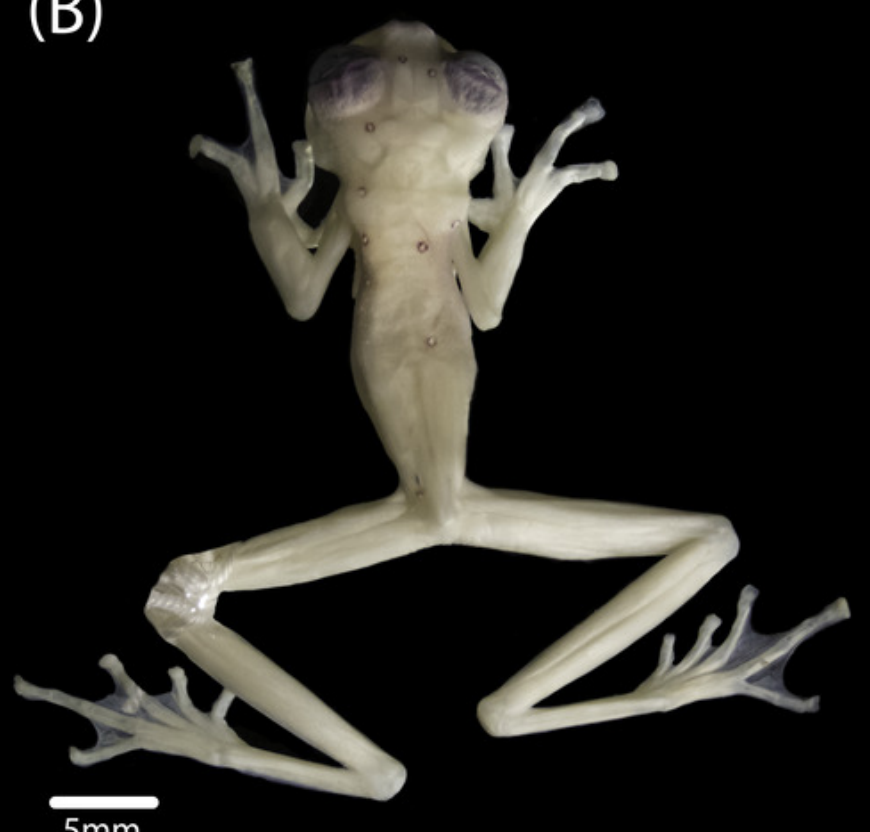

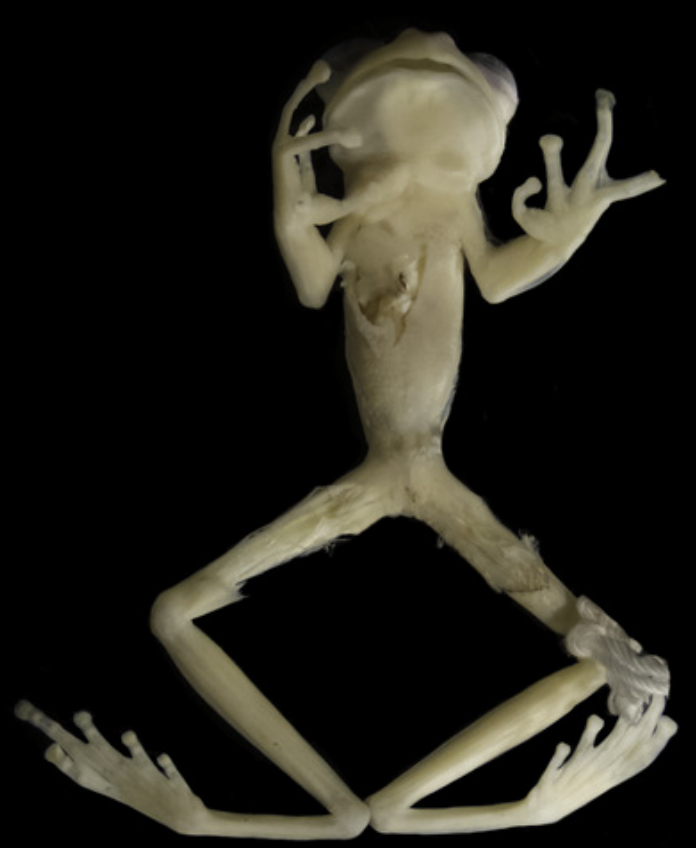

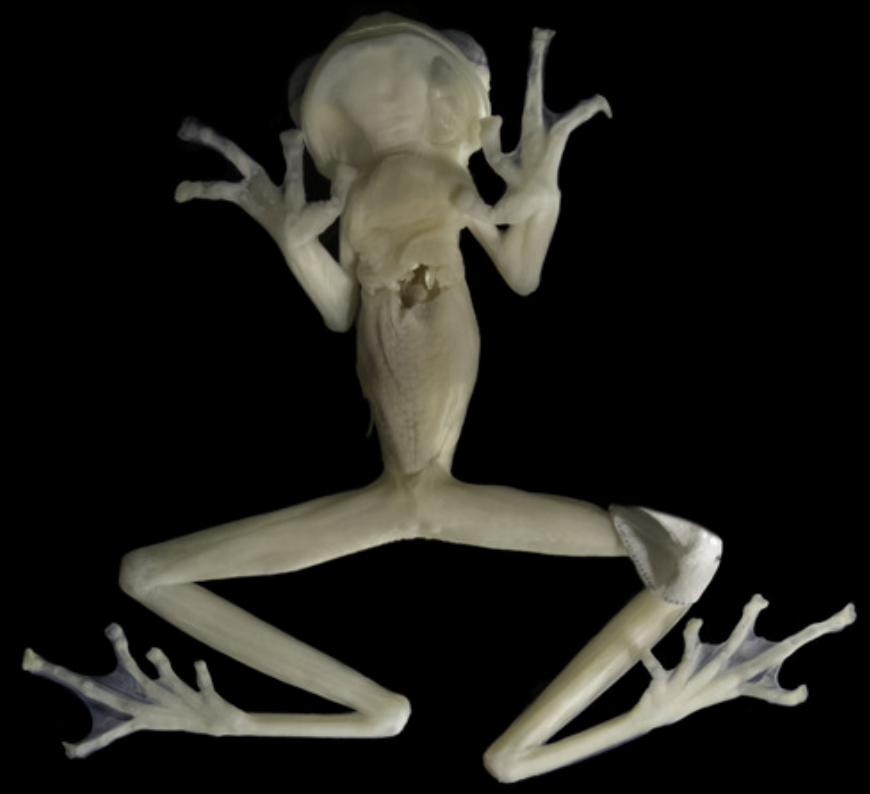


Figure 4

Figure 4

Nymphargus laurae (INABI015383), (A) dorsal view, (B) side view, (C) front view and (D) ventral view.
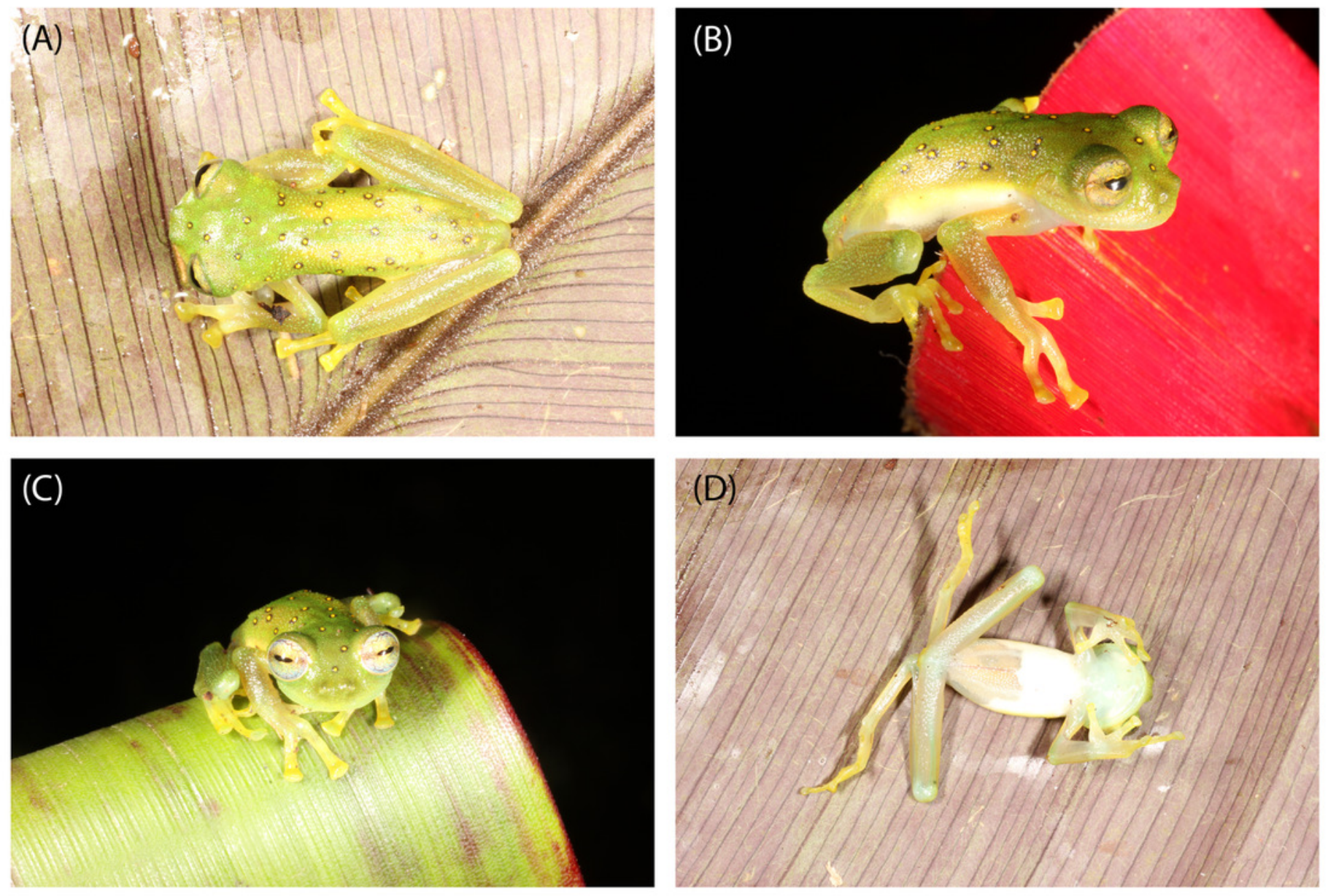


\title{
Figure 5
}

\author{
Figure 5
}

Optimal maximum likelihood tree (log likelihood $=-28155.635)$ of Nymphargus (the clade including $N$. laurae is highlighted by an orange rectangle) inferred from concatenated DNA sequences of fragments of the mitochondrial genes 12S, 16S, and COI, and the nuclear gen RAG1, totaling 2,823 aligned base pairs. Circles indicate significant support values for clades recovered by Bayesian (BA) and Likelihood (ML) analyses.

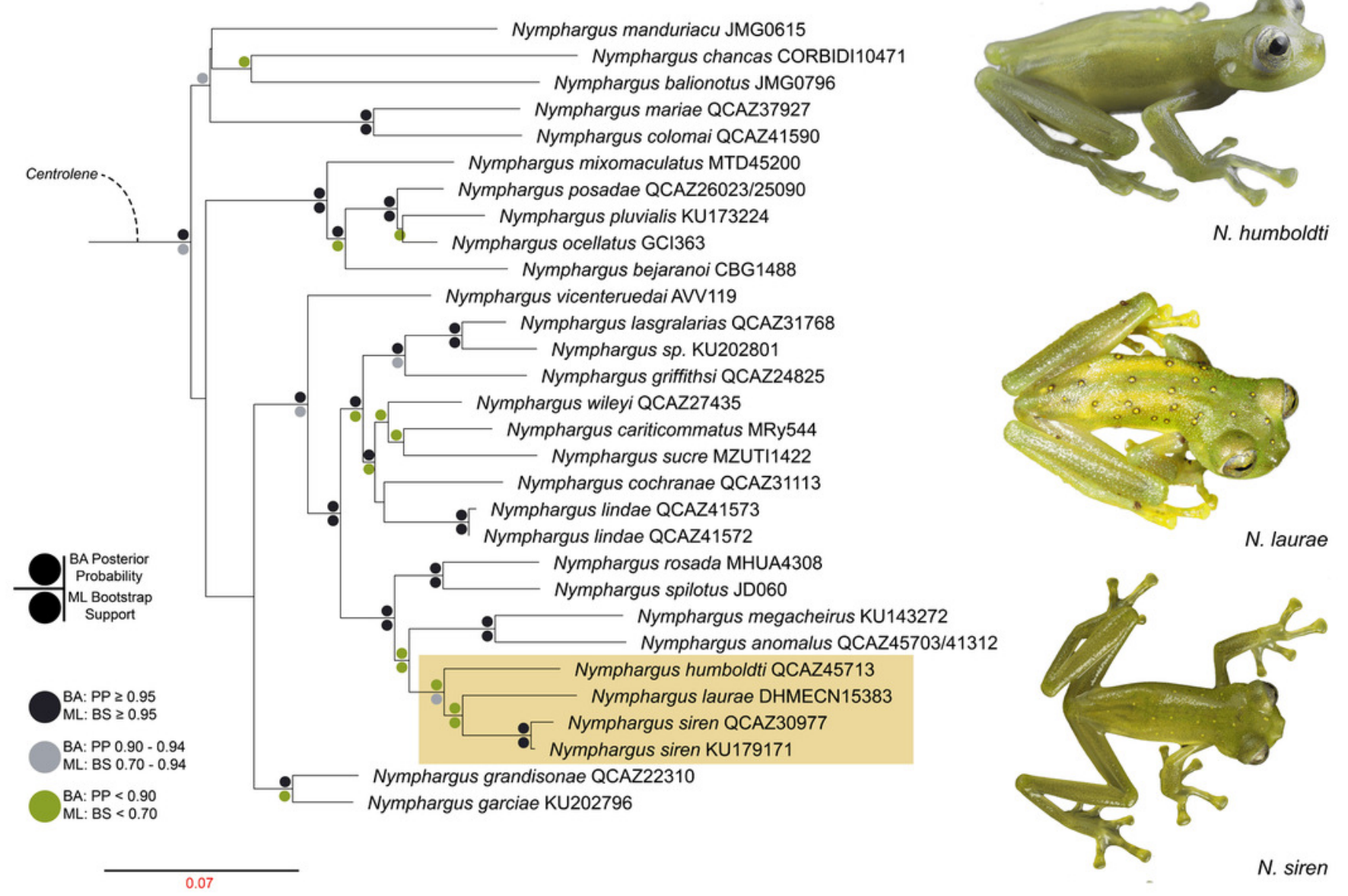




\section{Table $\mathbf{1}$ (on next page)}

Table 1

Morphometric measurements $(\mathrm{mm})$ in specimens of Nymphargus laurae. 


\section{Table 1:}

2 Morphometric measurements $(\mathbf{m m})$ in specimens of Nymphargus laurae.

3

\begin{tabular}{|c|c|c|c|}
\hline Character & $\begin{array}{l}\text { Male (Holotype) } \\
\text { USNM } 288453\end{array}$ & $\begin{array}{l}\text { Male } \\
\text { INABIO15384 }\end{array}$ & $\begin{array}{l}\text { Subadult female } \\
\text { INABIO15383 }\end{array}$ \\
\hline HW & 7.4 & 7.8 & 8.0 \\
\hline SVL & 19.9 & 22.1 & 22.3 \\
\hline $\mathrm{TL}$ & 11.7 & 13.8 & 13.6 \\
\hline IOD & 3.8 & 3.1 & 2.8 \\
\hline $\mathrm{HL}$ & 6.9 & 6.9 & 6.5 \\
\hline ED & 2.9 & 3.4 & 3.6 \\
\hline IND & 1.6 & 2.3 & 2.7 \\
\hline $\mathrm{EN}$ & 1.7 & 2.1 & 3.0 \\
\hline FL & 8.7 & 10.5 & 10.3 \\
\hline TD & - & 0.9 & 0.7 \\
\hline THL & - & 12.3 & 11.7 \\
\hline $\mathrm{SL}$ & - & 3.1 & 2.8 \\
\hline FLL & - & 5.0 & 4.4 \\
\hline UEW & - & 2.1 & 2.9 \\
\hline HAL & - & 7.8 & 7.4 \\
\hline Fin 4DW & - & 1.5 & 2.0 \\
\hline HW/HL & 1.1 & 1.1 & 1.2 \\
\hline HW/SVL & 0.4 & 0.4 & 0.4 \\
\hline HL/SVL & 0.4 & 0.3 & 0.3 \\
\hline $\mathrm{EN} / \mathrm{HL}$ & 0.3 & 0.3 & 0.5 \\
\hline $\mathrm{ED} / \mathrm{HL}$ & 0.4 & 0.5 & 0.5 \\
\hline IOD/ED & 1.3 & 0.9 & 0.8 \\
\hline $\mathrm{EN} / \mathrm{ED}$ & 0.6 & 0.6 & 0.8 \\
\hline EN/IOD & 0.5 & 0.7 & 1.1 \\
\hline TL/SVL & 0.6 & 0.6 & 0.6 \\
\hline FL/SVL & 0.4 & 0.5 & 0.5 \\
\hline HAL/SVL & - & 0.4 & 0.3 \\
\hline FLL/SVL & - & 0.2 & 0.2 \\
\hline ED/Fin 4DW & - & 2.3 & 1.8 \\
\hline
\end{tabular}

